\title{
Epidemiology of gout in Hong Kong: a population-based study from 2006 to 2016
}

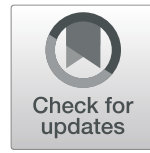

Tsoi Man Fung ${ }^{1}$, Chung Man Ho ${ }^{2}$, Cheung Bernard Man Yung ${ }^{1,3,4}$, Lau Chak Sing ${ }^{1}$ and Cheung Tommy Tsang ${ }^{1,5^{*}}$ (D)

\begin{abstract}
Objective: To determine the incidence and prevalence of gout in the general population and the utilisation of urate-lowering therapy (ULT) among patients with gout in Hong Kong.

Methods: A total of 2,741,862 subjects who attended any outpatient clinics or accident and emergency department (with or without hospitalisation) in 2005 and did not die before 2006 were identified from the Clinical Data Analysis and Reporting System (CDARS) of the Hospital Authority in Hong Kong. All subjects were followed until the end of 2016 or death.

Demographics, diagnosis of gout, serum urate levels, and ULT prescriptions were retrieved from CDARS. Gout was defined by the diagnosis codes in CDARS. The serum urate levels achieved after prescribing ULT were the means of all serum urate levels measured 6 months after prescriptions. Results were analysed by R version 3.3.3 with package 'prevalence' version 0.4.0.
\end{abstract}

Results: The crude incidence of gout increased from 113.05/100,000 person-years (PY) in 2006 to 211.62/100,000 PY in 2016. The crude prevalence of gout increased from $1.56 \%$ in 2006 to $2.92 \%$ in 2016. Only $25.55 \%$ of patients with gout were prescribed ULT in 2016. 35.8\% of patients treated with ULT were able to achieve the target serum urate level of $<6 \mathrm{mg} / \mathrm{dL}$.

Conclusions: Population ageing as well as other risk factors contributed to an increase in the incidence and prevalence of gout in Hong Kong. In 2016, the crude prevalence of gout in Hong Kong was comparable to that in many western countries. However, only one in four patients with gout in Hong Kong was prescribed ULT.

Keywords: Gout, Hong Kong, Epidemiology, Urate-lowering therapy

\section{Introduction}

Gout is the most common inflammatory arthritis caused by deposition of monosodium urate crystals in peripheral joints. Although the prevalence of gout was estimated to be $0.08 \%$ globally [1], it has increased significantly over the last decade, especially in developed countries and Oceanic populations. The estimated prevalence of gout in the United States (US), UK, and European countries is

\footnotetext{
*Correspondence: tcheungt@hku.hk

'Department of Medicine, The University of Hong Kong, Pokfulam, Hong Kong, China

${ }^{5}$ Department of Medicine, Hong Kong Sanatorium \& Hospital, 2 Village Road, Happy Valley, Hong Kong, China

Full list of author information is available at the end of the article
}

$2-3 \%[2,3]$. Asian countries and regions except Taiwan are considered to have a lower prevalence of gout due to differences in ethnicity and lifestyle $[4,5]$.

The American College of Rheumatology (ACR) and European League Against Rheumatism (EULAR) recommend urate-lowering therapy (ULT) in all patients with recurrent flare, tophi, chronic kidney disease, and urolithiasis. In particular, EULAR also recommends initiation of ULT close to the time of first diagnosis in patients with earlyonset gout or with a very high baseline serum urate level. The target serum urate level should be maintained below 6 $\mathrm{mg} / \mathrm{dL}$ but not less than $3 \mathrm{mg} / \mathrm{dL}$ in the long-term $[6,7]$.

A local retrospective study of 279 subjects reported that $70 \%$ of patients with gout were prescribed ULT.

\section{$\triangle B M C$}

(c) The Author(s). 2020 Open Access This article is licensed under a Creative Commons Attribution 4.0 International License, which permits use, sharing, adaptation, distribution and reproduction in any medium or format, as long as you give appropriate credit to the original author(s) and the source, provide a link to the Creative Commons licence, and indicate if changes were made. The images or other third party material in this article are included in the article's Creative Commons licence, unless indicated otherwise in a credit line to the material. If material is not included in the article's Creative Commons licence and your intended use is not permitted by statutory regulation or exceeds the permitted use, you will need to obtain permission directly from the copyright holder. To view a copy of this licence, visit http://creativecommons.org/licenses/by/4.0/ The Creative Commons Public Domain Dedication waiver (http://creativecommons.org/publicdomain/zero/1.0/) applies to the data made available in this article, unless otherwise stated in a credit line to the data. 
However, the study results could not be generalised to the population because it was conducted in a family medicine training centre [8]. Due to the lack of latest epidemiological data on gout in Hong Kong, we conducted this population-based study to determine the incidence and prevalence of gout as well as the utilisation of ULT among patients with gout in Hong Kong.

\section{Methods}

The Hospital Authority (HA) is the only public healthcare provider in Hong Kong. More than $90 \%$ of Hong Kong citizens utilise the public healthcare service [9].
The Clinical Data Analysis and Reporting System (CDARS) is a database managed and updated daily by the HA [10]. This database captures clinical parameters of each public healthcare service user. These parameters include patient demographics, death, diagnoses, hospital admissions, procedures performed, laboratory parameters, medication prescriptions, and dispensing histories. It has been used to conduct high-quality epidemiological studies of infectious and rheumatic diseases $[9,11]$.

We included all subjects who attended any outpatient clinics or accident and emergency department (with or without hospitalisation) in 2005. Since all the data are

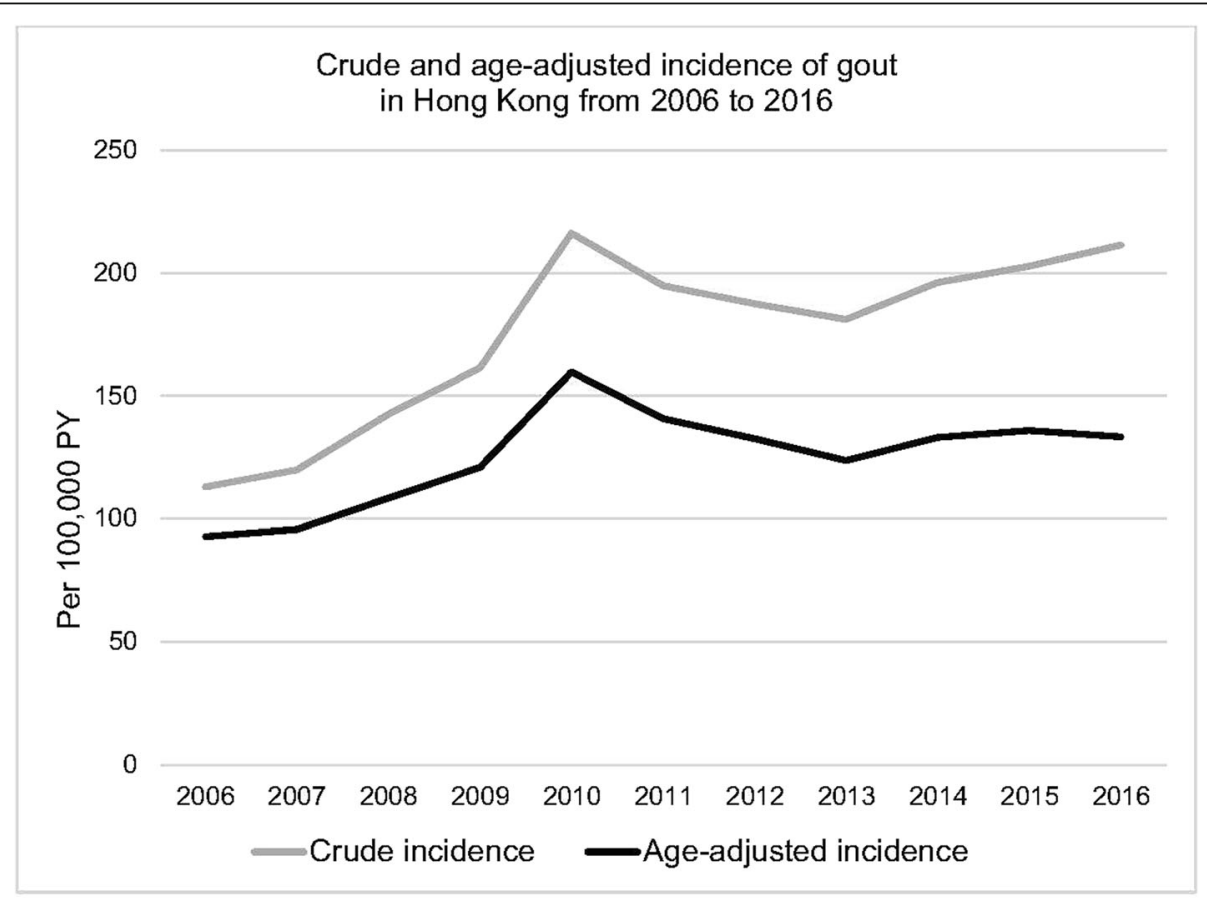

\begin{tabular}{|c|c|c|c|c|c|c|}
\hline \multirow[t]{2}{*}{ Year } & \multirow{2}{*}{$\begin{array}{l}\text { Incident } \\
\text { cases }\end{array}$} & \multirow[t]{2}{*}{ PY } & \multicolumn{3}{|c|}{ Incidence $[95 \% \mathrm{Cl}](/ 100000 \mathrm{PY})$} & \multirow{2}{*}{$\begin{array}{c}\text { Age-adjusted } \\
\text { incidence [95\% Cl] } \\
(/ 100000 \mathrm{PY})\end{array}$} \\
\hline & & & Male & Female & Overall & \\
\hline 2006 & 2458 & $2,174,284$ & $\begin{array}{c}191.96 \\
{[183.04-200.88]}\end{array}$ & $\begin{array}{c}54.39 \\
{[20.39-55.58]}\end{array}$ & $\begin{array}{c}113.05 \\
{[108.58-117.52]}\end{array}$ & $\begin{array}{c}92.92 \\
{[91.03-94.81]}\end{array}$ \\
\hline 2007 & 2570 & $2,143,021$ & $\begin{array}{c}196.84 \\
{[187.72-205.96]}\end{array}$ & $\begin{array}{c}144.96 \\
{[138.24-151.67]}\end{array}$ & $\begin{array}{c}119.92 \\
{[115.29-124.56]}\end{array}$ & $\begin{array}{c}95.70 \\
{[93.77-97.64]}\end{array}$ \\
\hline 2008 & 3014 & $2,111,648$ & $\begin{array}{c}222.99 \\
{[213.19-232.79]}\end{array}$ & $\begin{array}{c}163.07 \\
{[155.91-170.24]}\end{array}$ & $\begin{array}{c}142.73 \\
{[137.64-147.83]}\end{array}$ & $\begin{array}{c}108.66 \\
{[106.31-111.01]}\end{array}$ \\
\hline 2009 & 3362 & $2,080,926$ & $\begin{array}{c}253.70 \\
{[243.15-264.25]}\end{array}$ & $\begin{array}{c}184.24 \\
{[176.58-191.91]}\end{array}$ & $\begin{array}{c}161.56 \\
{[156.10-167.02]}\end{array}$ & $\begin{array}{c}120.96 \\
{[118.47-123.45]}\end{array}$ \\
\hline 2010 & 4434 & $2,049,464$ & $\begin{array}{c}337.19 \\
{[324.91-349.47]}\end{array}$ & $\begin{array}{c}243.10 \\
{[234.24-251.95]}\end{array}$ & $\begin{array}{c}216.35 \\
{[209.98-222.72]}\end{array}$ & $\begin{array}{c}159.94 \\
{[156.69-163.19]}\end{array}$ \\
\hline 2011 & 3936 & $2,018,358$ & $\begin{array}{c}302.56 \\
{[290.81-314.31]}\end{array}$ & $\begin{array}{c}216.48 \\
{[208.07-224.89]}\end{array}$ & $\begin{array}{c}195.01 \\
{[188.92-201.10]}\end{array}$ & $\begin{array}{c}140.88 \\
{[137.97-143.78]}\end{array}$ \\
\hline 2012 & 3728 & $1,988,127$ & $\begin{array}{c}285.28 \\
{[273.77-296.80]}\end{array}$ & $\begin{array}{c}202.71 \\
{[194.52-210.89]}\end{array}$ & $\begin{array}{c}187.51 \\
{[181.49-193.53]}\end{array}$ & $\begin{array}{c}132.72 \\
{[130.10-135.34]}\end{array}$ \\
\hline 2013 & 3549 & $1,928,563$ & $\begin{array}{c}266.30 \\
{[255.06-277.53]}\end{array}$ & $\begin{array}{c}187.94 \\
{[180.01-195.86]}\end{array}$ & $\begin{array}{c}181.20 \\
{[175.24-187.16]}\end{array}$ & $\begin{array}{c}123.92 \\
{[121.36-126.48]}\end{array}$ \\
\hline 2014 & 3787 & $1,928,563$ & $\begin{array}{c}287.36 \\
{[275.58-299.15]}\end{array}$ & $\begin{array}{c}201.46 \\
{[193.20-209.72]}\end{array}$ & $\begin{array}{c}196.36 \\
{[190.11-202.62]}\end{array}$ & $\begin{array}{c}133.28 \\
{[130.58-135.99]}\end{array}$ \\
\hline 2015 & 3853 & $1,898,718$ & $\begin{array}{c}294.57 \\
{[282.52-306.62]}\end{array}$ & $\begin{array}{c}205.13 \\
{[196.74-213.52]}\end{array}$ & $\begin{array}{c}202.93 \\
{[196.52-209.33]}\end{array}$ & $\begin{array}{c}136.18 \\
{[132.88-139.49]}\end{array}$ \\
\hline 2016 & 3955 & $1,868,911$ & $\begin{array}{c}306.48 \\
{[294.07-318.89]}\end{array}$ & $\begin{array}{c}212.00 \\
{[203.41-220.58]}\end{array}$ & $\begin{array}{c}211.63 \\
{[205.03-218.22]}\end{array}$ & $\begin{array}{c}133.50 \\
{[129.96-137.04]}\end{array}$ \\
\hline
\end{tabular}

Fig. 1 Incidence of gout in Hong Kong from 2006 to 2016 
anonymised in CDARS, each user was assigned a unique reference key and it was used to identify duplicate records in different datasets, i.e. outpatient clinics and accident and emergency department visits. Subjects who died before 1 January 2006 were excluded. Clinical data including demographics, diagnosis of gout, serum urate levels, and prescriptions of ULT were retrieved from CDARS from 1 January 2006 to 31 December 2016.

All subjects were followed until the cut-off date (31 December 2016) or death. Gout was defined as physician-diagnosed gout according to the International Classification of Diseases 9th Edition diagnosis codes. These diagnosis codes include gouty arthropathy (274.0), gouty nephropathy (274.1), gouty tophi of the ear (274.81), gout with other specified manifestations (274.89), and unspecified gout (274.9). Validation of diagnosis was performed by a certified rheumatologist. This was conducted by accessing 500 electronic records of patients with gout and the same number of electronic records of patients without gout from Queen Mary Hospital. A positive predictive value of $97.5 \%$ and negative predictive value of $98.7 \%$ were demonstrated.

We defined the incidence of gout as the number of incident cases divided by the number of person-years (PY). The prevalence of gout was defined as the number of prevalent cases divided by the number of people included at the end of each calendar year.

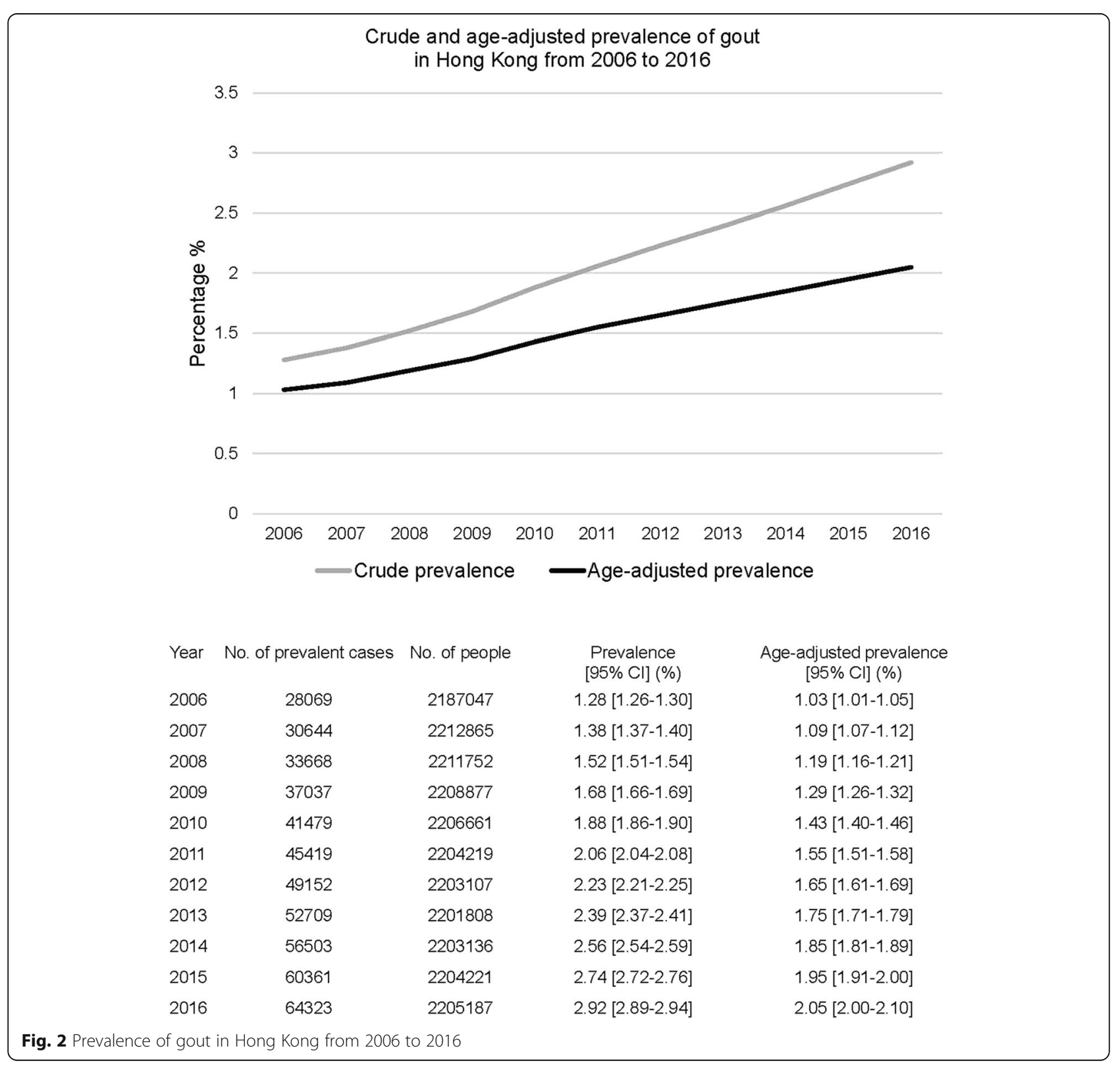


The prescription of ULT was defined as a continuous prescription of ULT for more than 30 days. Benzbromarone, sulfinpyrazone, and peticoglycase were not included because they were not available in the HA drug formulary [12]. Therefore, we only estimated the percentages of patients prescribed allopurinol, febuxostat, or probenecid. In patients treated with ULT, only the serum urate levels measured 6 months after commencement of ULT were included for analysis. Mean serum urate levels and percentages of patients achieving the treatment target were stratified by sex and the use of ULT.

Results were analysed by R version 3.3.3 (https://www. R-project.org/) with package 'prevalence' version 0.4.0. Incidence rate, prevalence, and their 95\% confidence intervals (CIs) were estimated. Age- and sex-adjusted incidence and the prevalence of gout were adjusted based on the population data released by the Census and Statistics Department, The Hong Kong Special Administrative Region Government [13]. We used population data in 2006 as the reference population in this study. Ageand sex-specific incidence and prevalence, and male-tofemale incidence rate ratio and prevalence ratio were also estimated.

This study was approved by the Institutional Review Board of the University of Hong Kong/Hospital Authority Hong Kong West Cluster (IRB reference number: UW-533).

\section{Results}

A total of 4,864,094 patients were identified in CDAR $\mathrm{S}$ in 2005. After excluding 2,052,702 duplicate records and 69,530 deaths in 2005, 2,741,862 patients were included in the analysis. A summary of subject inclusion is summarised in Supplementary Fig. S1. The crude incidence $[95 \% \mathrm{CI}]$ of gout increased from
$113.05[108.58-117.52] / 100,000$ PY in 2006 to 211.62 [205.03-218.22]/100,000 PY in 2016. The age-adjusted incidence of gout showed an increase from 92.92 [91.03-94.81]/100,000 PY in 2006 to 112.52 [110.05115.00]/100,000 PY in 2016 (Fig. 1). There was also a steady increase in the incidence of gout in both sexes. The age- and sex-adjusted incidence of gout tripled from 99.41 [97.70-101.12]/100,000 PY in 2006 to 294.74 [285.67-303.80]/100,000 PY in 2016 (Supplementary Table S1).

The crude prevalence [ $95 \% \mathrm{CI}]$ of gout increased from $1.28[1.26-1.30] \%$ in 2006 to $2.92[2.89-2.94] \%$ in 2016. The age-adjusted prevalence of gout increased from 1.03 [1.01-1.05] \% in 2006 to 2.05 [2.00-2.10] \% in 2016 (Fig. 2). The age- and sex-adjusted prevalence of gout in 2006-2016 in Hong Kong is summarised in Supplementary Table S1. The age- and sex-adjusted prevalence of gout doubled from 1.08 [1.06-1.10] \% in 2006 to 1.84 [1.81-1.86] \% in 2016.

The age- and sex-specific incidence and prevalence of gout in 2016 in Hong Kong were summarised in Supplementary Table S2 and S3, respectively. The age-specific incidence and prevalence of gout in both sexes increased in a non-linear fashion. $6.26 \%$ of the general population aged 80 years or older had gout in 2016. The incidence and prevalence of gout in male were higher than in female across all age groups. However, both the incidence ratio and prevalence ratio decreased with increasing age.

Despite the increase in incidence and prevalence of gout in Hong Kong, the utilisation of ULT remained low. In 2016, only $25.5 \%$ of patients with gout were prescribed ULT. Female patients with gout were less often prescribed ULT than male patients. The most commonly prescribed ULT was allopurinol, and its average doses are summarised in Table 1. Among patients treated with

Table 1 Mean doses of allopurinol prescribed for patients with gout from 2006 to 2016

\begin{tabular}{|c|c|c|c|}
\hline \multirow[t]{2}{*}{ Year } & \multicolumn{3}{|c|}{ Mean doses of allopurinol [95\% Cl] } \\
\hline & Male & Female & Overall \\
\hline 2006 & $145.03[143.39-146.68]$ & $126.13[124.18-128.12]$ & 139.19 [137.90-140.50] \\
\hline 2007 & 145.17 [143.55-126.13] & 126.13 [124.20-128.08] & 139.34 [138.05-140.63] \\
\hline 2008 & 147.00 [145.41-126.07] & 126.07 [124.18-127.99] & 140.59 [139.33-141.86] \\
\hline 2009 & 148.60 [147.06-150.15] & 125.90 [124.09-127.75] & 141.71 [140.49-142.94] \\
\hline 2010 & 150.15 [148.67-151.65] & 126.79 [125.02-128.60] & 143.09 [141.91-144.28] \\
\hline 2011 & 151.78 [150.33-153.24] & 128.05 [126.28-129.85] & 144.69 [143.53-145.85] \\
\hline 2012 & 153.19 [151.77-154.64] & 129.67 [127.93-131.43] & 146.13 [144.99-147.28] \\
\hline 2013 & 154.27 [152.85-155.70] & $129.41[127.69-131.15]$ & 146.81 [145.68-147.95] \\
\hline 2014 & 154.57 [153.18-155.97] & 129.67 [127.98-131.38] & 147.10 [145.99-148.22] \\
\hline 2015 & 154.34 [152.98-155.71] & 128.14 [126.50-129.80] & 146.43 [145.35-147.53] \\
\hline 2016 & 153.55 [152.24-154.87] & 127.44 [125.85-129.05] & 145.66 [144.61-146.71] \\
\hline
\end{tabular}


allopurinol, all of them use it for more than 1 year and the mean duration of allopurinol therapy was 5 years. However, the mean time lag between diagnosis and treatment was 2.18 [2.17-2.19] years. Less than $1 \%$ of patients were prescribed febuxostat or probenecid (Fig. 3).

There was a steady decrease in the mean serum urate levels in patients with gout from 2006 to 2016 as illustrated in Fig. 4. Female patients and patients treated with ULT had lower serum urate levels. In 2016, the mean serum urate levels in patients with or without ULT prescriptions were $7.88 \mathrm{mg} / \mathrm{dL}$ and $7.13 \mathrm{mg} / \mathrm{dL}$ respectively.
The estimated proportions of patients who were able to achieve the treatment target $(<6 \mathrm{mg} / \mathrm{dL})$ are illustrated in Fig. 5. In general, patients treated with ULT were more likely to achieve the treatment target and the percentage also increased from 19.5 to $28.1 \%$ from 2006 to 2016. Although less female patients were prescribed ULT, they were more likely to achieve the treatment target than male patients.

\section{Discussion}

This is the latest population-based study that investigates the incidence and prevalence of gout in Hong Kong.

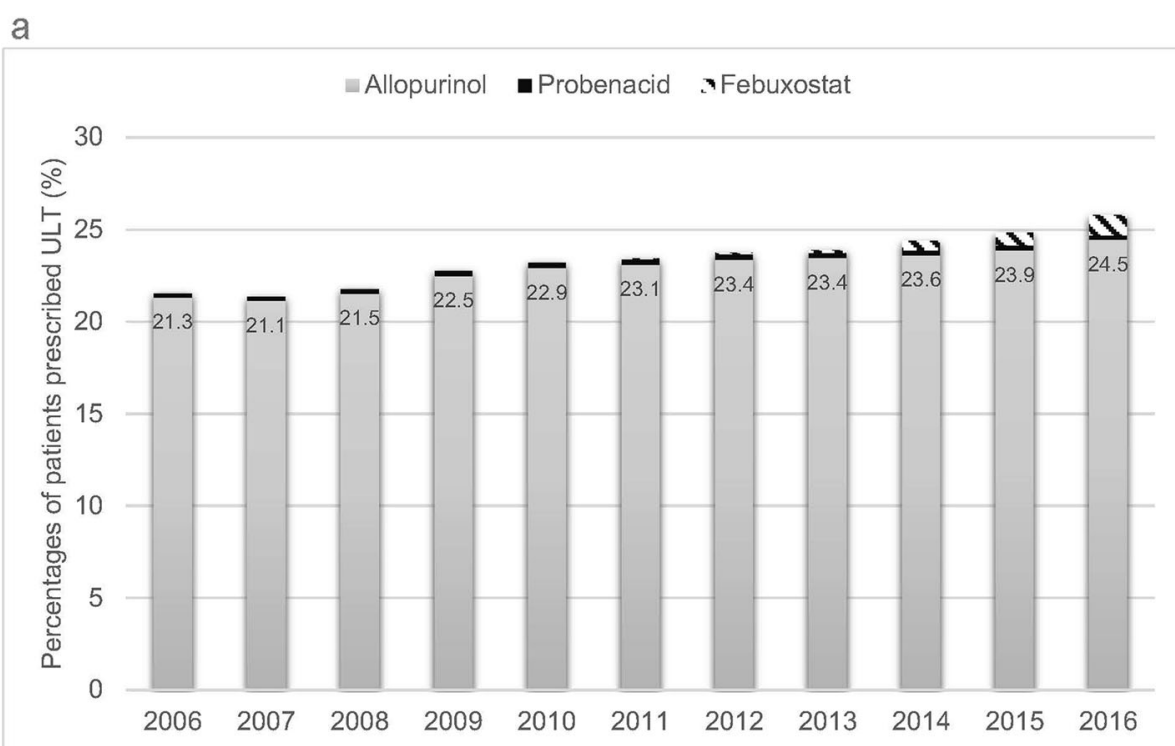

(Numbers on top of the bars represent the percentages of patients prescribed allopurinol)

b

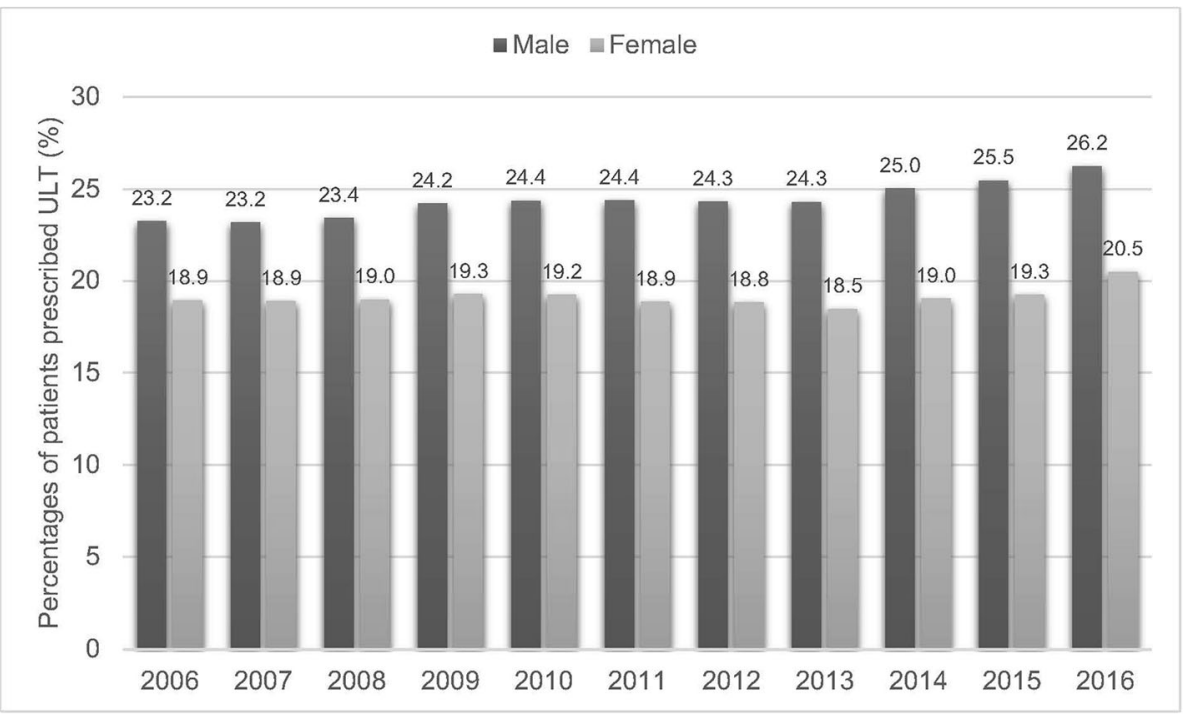

Fig. 3 a Use of ULT in Hong Kong from 2006 to 2016. b Use of ULT stratified by sex from 2006 to 2016 

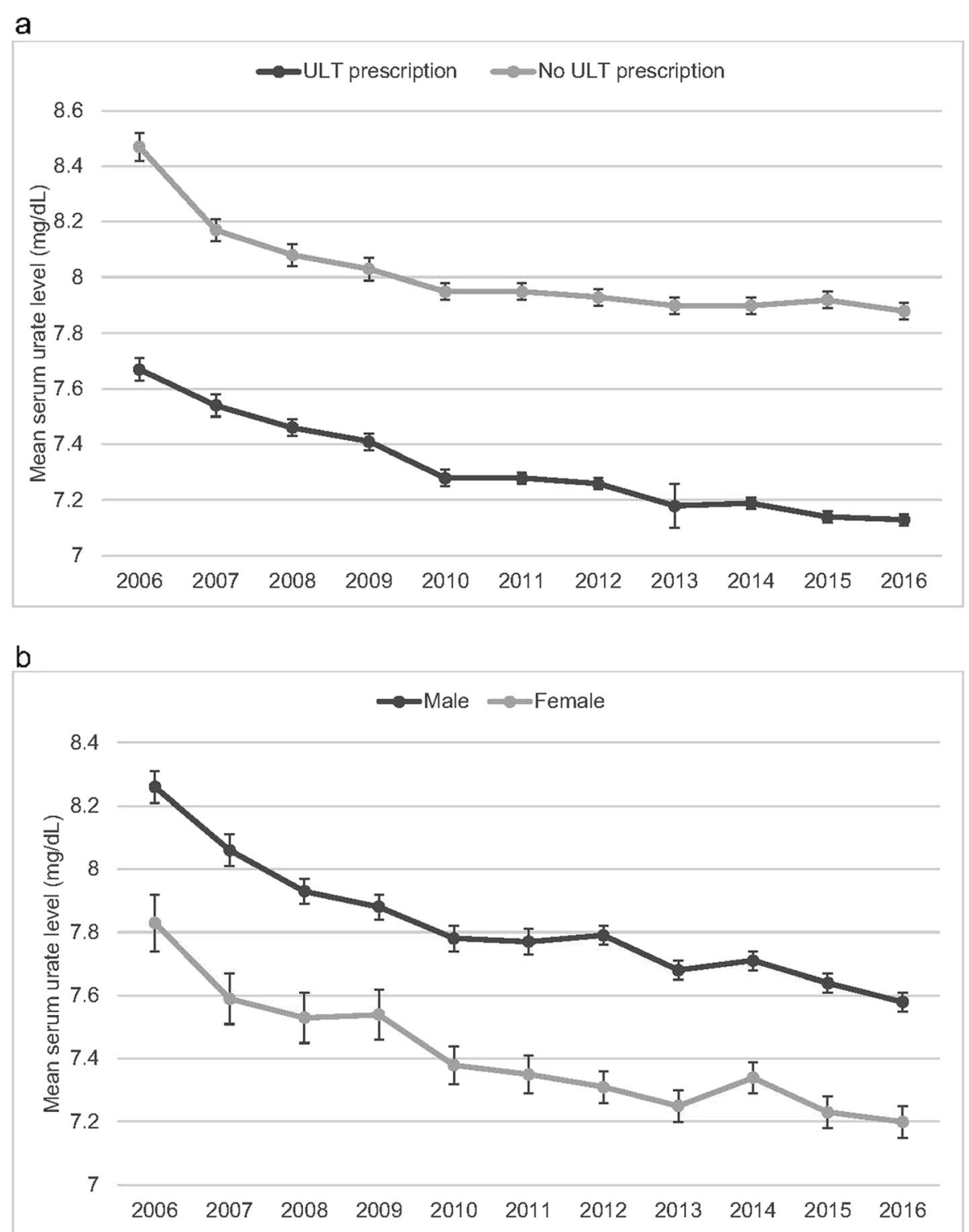

Fig. 4 a Mean serum urate levels in patients with gout from 2006 to 2016. b Mean serum urate levels in patients with gout stratified by sex

Subjects included in this study are representative of the general population. We reported an increase in the incidence and prevalence of gout in Hong Kong. Ageing population is definitely one of the contributing factors. The number of Hong Kong people aged $\geq 65$ years increased from $865,200(12.5 \%)$ in 2006 to $1,192,700$ $(16.1 \%)$ in 2015 [14]. As population ageing continues, we expected the crude incidence and prevalence of gout will further increase.

Our study also showed a non-linear increase in agespecific incidence and prevalence of gout. This phenomenon was also shown in a population-based study in Taiwan [4]. The incidence of gout was highest at the age $\geq 80$ because this age group had the highest number of incident cases but the lowest PY.

The latest incidence and prevalence of gout in Hong Kong were similar to those in the western countries, including the UK [2, 15], New Zealand [16], Denmark [17], Australia [18], and the US according to the US National Health Nutrition and Examination Survey in 2015-2016 [18]. However, the prevalence of gout did not increase in the US.

An increase in both the age- and sex-adjusted incidence and prevalence suggested that other risk factors, including alcohol consumption, obesity, and diabetes, might contribute to this observation. The Population 

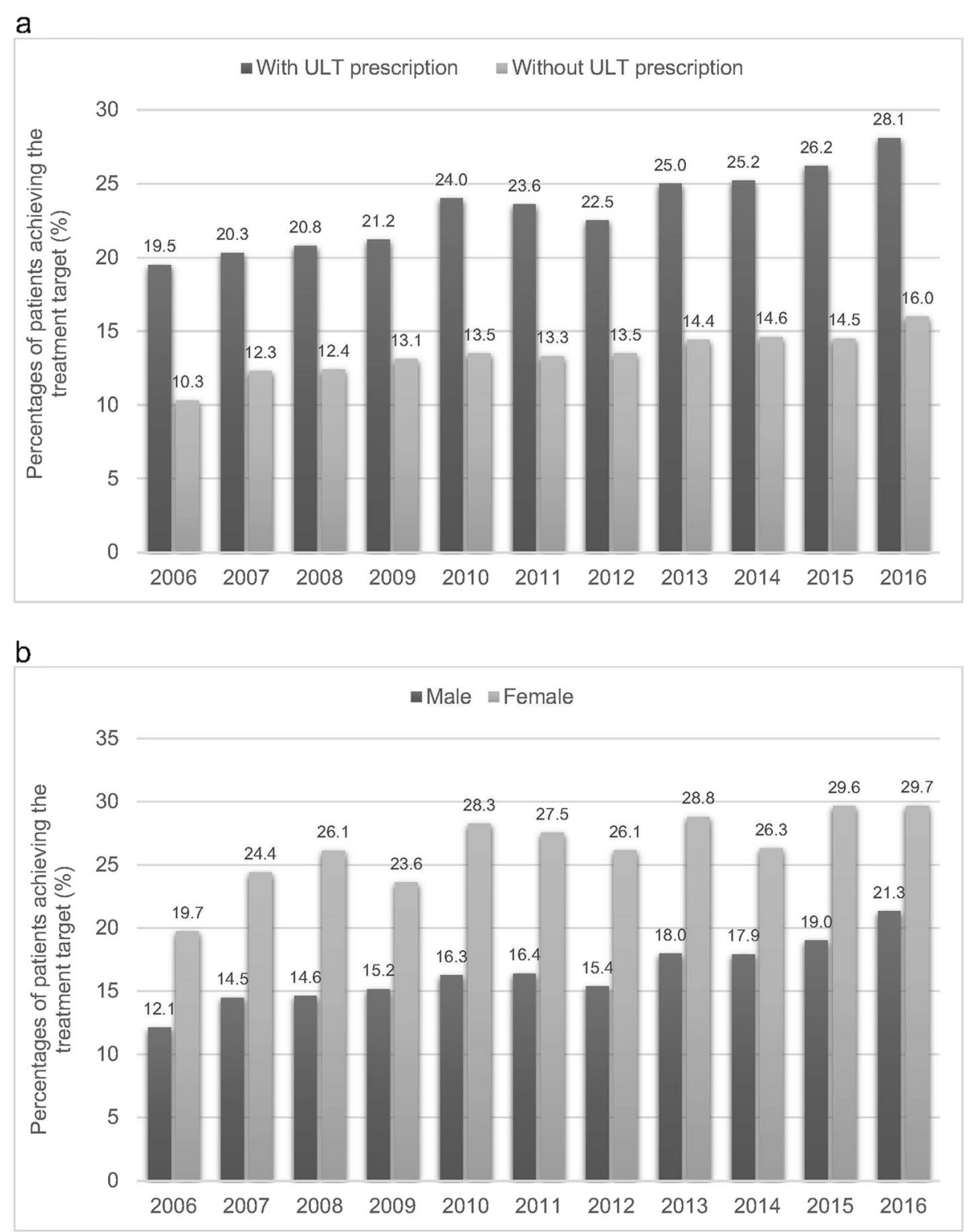

Fig. 5 a Percentages of patients with gout who can achieve the treatment target $(<6 \mathrm{mg} / \mathrm{dL})$ from 2006 to 2016 . $\mathbf{b}$ Percentages of patients with gout who can achieve the treatment target $(<6 \mathrm{mg} / \mathrm{dL})$ stratified by sex

Health Survey showed that the proportion of Hong Kong people with overweight or obesity increased from $38.8 \%$ in $2003 / 2004$ to $50.0 \%$ in $2014 / 2015$ [ 14 , 19]. Results of this survey also showed that there was an increase in regular alcohol consumption. The proportion of population with regular alcohol consumption increased from $9.5 \%$ in $2003 / 2004$ to $11.1 \%$ in $2013 / 2014$, while the prevalence of self-reported diabetes increased from 3.8 to $5.5 \%$. Although CDARS does not capture body mass index and alcohol consumption, results of this survey may explain the increase in the incidence and prevalence of gout beyond population ageing.
The management of gout remained suboptimal in Hong Kong because the utilisation of ULT was insufficient [4]. The prescription of febuxostat was less than $1 \%$ because it was not subsidised by the government. Although allopurinol was fully subsidised, only $24.5 \%$ of patients with gout received this medication [12].

The efficacy of ULT in reducing serum urate levels has been demonstrated in many randomised controlled trials. In addition, the use of xanthine oxidase inhibitors in patients with gout is associated with cardiovascular and renal benefits. Epidemiological studies suggested that allopurinol might decrease mortality in patients with congestive heart failure and the risk of myocardial infarction [20]. However, 
allopurinol is associated with an increased risk of severe cutaneous adverse reaction in patients carrying the HLAB*5801 allele. According to a population-based study conducted in Taiwan, among Han Chinese who carry the HLA-B*5801 allele are 580 times more likely to develop allopurinol-induced severe cutaneous adverse reaction than those who do not carry the allele [21]. Although febuxostat is more effective than allopurinol, it is associated with increased cardiovascular and all-cause mortality compared to allopurinol [22]. It is worth noting that the results have been criticised due to high drop-out and many other methodological issues. Nevertheless, many studies have confirmed that hyperuricaemia is associated with increased mortality, and therefore, ULT should be considered seriously in patients with gout.

\section{Limitation}

This study is not without limitations. We used the diagnosis codes in CDARS; therefore, the diagnostic accuracy depends on physician's coding. Compliance to ULT cannot be captured in CDARS. Therefore, the effect of compliance to ULT on serum urate levels among patients with gout cannot be assessed in this study. In addition, not all patients with gout had a serum urate level measurement. Therefore, the mean serum urate levels cannot represent all the patients with gout in this study. Although we covered more than $90 \%$ of the general population in Hong Kong, CDARS does not include patients receiving medical care in the private sector. This social bias could not be remedied as socioeconomic data are not included in the database.

\section{Conclusion}

Population ageing contributes to an increase in the incidence and prevalence of gout in Hong Kong. The crude prevalence of gout in Hong Kong was 2.92\% in 2016, which is comparable to that reported in other western countries. Despite an increase in the prevalence of gout, the utilisation of ULT remained low. Only one in four patients with gout was prescribed urate-lowering agents.

\section{Supplementary information}

Supplementary information accompanies this paper at https://doi.org/10. 1186/s13075-020-02299-5.

\section{Additional file 1: Supplementary Fig. S1. Subject inclusion.}

Additional file 2: Supplementary Table S1. Age- and sex-adjusted incidence and prevalence of gout in Hong Kong from 2006 to 2016. Supplementary Table S2. Age- and sex-specific incidence of gout in Hong Kong in 2016. Supplementary Table S3. Age- and sex-specific prevalence of gout in Hong Kong in 2016.

\section{Abbreviations}

US: United States; ACR: American College of Rheumatology;

EULAR: European League Against Rheumatism; ULT: Urate-lowering therapy; HA: Hospital Authority; CDARS: Clinical Data Analysis and Reporting System; PY: Person-years; Cl: Confidence interval

\section{Acknowledgements}

We thank Mr. Ken Kong and Ms. Dorothy Lam for their technical assistance in retrieving the data for this study.

\section{Authors' contributions}

MFT and TTC designed the study, interpreted the data, and drafted the manuscript. MFT performed the statistical analysis. MHC, BMYC, and CSL contributed to the interpretation of data and revision of the manuscript substantively. The authors read and approved the final manuscript.

\section{Funding}

There was no funding support for this research.

\section{Availability of data and materials}

The datasets used and analysed during the current study are available from the corresponding author on reasonable request.

\section{Ethics approval and consent to participate}

This study has been approved by the Institutional Review Board of the University of Hong Kong/Hospital Authority Hong Kong West Cluster (IRB reference number: UW-533) for conducting this research.

\section{Consent for publication}

All authors have approved the final version of the manuscript and consented for publication.

\section{Competing interests}

The authors declare that they have no completing interests.

\section{Author details}

${ }^{1}$ Department of Medicine, The University of Hong Kong, Pokfulam, Hong Kong, China. ²Department of Medicine, Queen Mary Hospital, Pokfulam, Hong Kong, China. ${ }^{3}$ Partner State Key Laboratory of Pharmaceutical Biotechnology, The University of Hong Kong, Pokfulam, Hong Kong, China. ${ }^{4}$ Research Centre of Heart Brain, Hormone and Healthy Aging, The University of Hong Kong, Pokfulam, Hong Kong, China. ${ }^{5}$ Department of Medicine, Hong Kong Sanatorium \& Hospital, 2 Village Road, Happy Valley, Hong Kong, China.

Received: 31 December 2019 Accepted: 24 August 2020

Published online: 04 September 2020

\section{References}

1. Kuo CF, Grainge MJ, Zhang W, et al. Global epidemiology of gout: prevalence, incidence and risk factors. Nat Rev Rheumatol. 2015;11(11):64962.

2. Cea Soriano L, Rothenbacher D, Choi HK, et al. Contemporary epidemiology of gout in the UK general population. Arthritis Res Ther. 2011;13(2):R39.

3. Chen-Xu M, Yokose C, Rai SK, et al. Contemporary prevalence of gout and hyperuricemia in the United States and decadal trends: the National Health and Nutrition Examination Survey 2007-2016. Arthritis Rheumatol. 2019. https://doi.org/10.1002/art.40807 [Epub ahead of print].

4. Kuo CF, Grainge MJ, See LC, et al. Epidemiology and management of gout in Taiwan: a nationwide population study. Arthritis Res Ther. 2015;17:13.

5. Lu X, Li X, Zhao Y, et al. Contemporary epidemiology of gout and hyperuricemia in community elderly in Beijing. Int J Rheum Dis. 2014;17: 400-7.

6. Richette P, Doherty M, Pascual E, et al. 2016 updated EULAR evidence-based recommendations for the management of gout. Ann Rheum Dis. 2017;76(1): 29-42.

7. Khanna D, Fitzgerald JD, Khanna PP, et al. American College of Rheumatology guidelines for management of gout. Part 1: systematic nonpharmacologic and pharmacologic therapeutic approaches to hyperuricemia. Arthritis Care Res (Hoboken). 2012;64(10):1431-46.

8. Kung K, Lam A, Li PKT. Review of the management of gout in a primary care clinic. Hong Kong Pract. 2004;26(7):301-8.

9. Mok CC, Kwok CL, Ho LY, et al. Life expectancy, standardized mortality ratios, and causes of death in six rheumatic diseases in Hong Kong, China. Arthritis Rheum. 2011;63(5):1182-9. https://doi.org/10.1002/art.30277.

10. HAHO/ITD/ Clinical Data Analysis \& Reporting System (CDARS) user's manual. In: Hospital Authority, second edition. Hong Kong; 2003. p. 3. 
11. Wong AY, Root A, Douglas IJ, et al. Cardiovascular outcomes associated with use of clarithromycin: population based study. BMJ. 2016;352:h6926.

12. Hospital Authority. Hospital Authority Drug Formulary 2018 [Available from: http://www.ha.org.hk/hadf/Portals/O/Docs/HADF_List/EL_Full\%20Ver_1 80113_pdf.] Accessed 16 June 2018.

13. Statistics and Census Department. [Available from: https:/www.censtatd. gov.hk/home/index_tc.jsp] Accessed 28 Jan 2018.

14. Centre for Health Protection [Available from: https://www.chp.gov.hk/files/ pdf/report_on_population_health_survey_2003_2004_en.pdf] Accessed 3 Jan 2019.

15. Kuo CF, Grainge MJ, Mallen C, et al. Rising burden of gout in the UK but continuing suboptimal management: a nationwide population study. Ann Rheum Dis. 2015;74(4):661-7.

16. Winnard D, Wright C, Taylor WJ, et al. National prevalence of gout derived from administrative health data in Aotearoa New Zealand. Rheumatology (Oxford). 2012;51(5):901-9.

17. Kristian Z, Daniel PA, René C, et al. Secular trends in the incidence and prevalence of gout in Denmark from 1995 to 2015: a nationwide registerbased study. Rheumatology (Oxford). 2018. https://doi.org/10.1093/ rheumatology/key390.

18. Ting K, Gill TK, Keen H, Tucker GR, Hill CL. Prevalence and associations of gout and hyperuricaemia: results from an Australian population-based study. Intern Med J. 2016;46(5):566-73.

19. Centre for Health Protection [Available from: https://www.chp.gov.hk/en/ static/51256.html] Accessed 3 Jan 2019.

20. Wei L, Fahey T, Struthers AD, MacDonald TM. Association between allopurinol and mortality in heart failure patients: a long-term follow-up study. Int J Clin Pract. 2009;63(9):1327-33.

21. Ko TM, Tsai CY, Chen SY, et al. Use of HLA-B*58:01 genotyping to prevent allopurinol induced severe cutaneous adverse reactions in Taiwan: national prospective cohort study. BMJ. 2015;351:h4848.

22. White WB, Sagg KG, Becker MA, et al. Cardiovascular safety of febuxostat or allopurinol in patients with gout. New Engl J Med. 2018;378:1200-10.

\section{Publisher's Note}

Springer Nature remains neutral with regard to jurisdictional claims in published maps and institutional affiliations.

Ready to submit your research? Choose BMC and benefit from:

- fast, convenient online submission

- thorough peer review by experienced researchers in your field

- rapid publication on acceptance

- support for research data, including large and complex data types

- gold Open Access which fosters wider collaboration and increased citations

- maximum visibility for your research: over $100 \mathrm{M}$ website views per year

At $\mathrm{BMC}$, research is always in progress.

Learn more biomedcentral.com/submissions 